\title{
The Use of Granulation to Reduce Dusting and Manage of Fine Coal
}

\author{
Małgorzata Ozga', Gabriel Borowski ${ }^{1 *}$ \\ 1 Faculty of Environmental Engineering, Lublin University of Technology, ul. Nadbystrzycka 40B, 20-618 Lublin, \\ Poland \\ * Corresponding author's e-mail: g.borowski@pollub.pl
}

\begin{abstract}
The development of mining and processing industries is accompanied by the formation of fine-grained waste materials that must undergo the treatment. Sometimes, grinding materials is a prerequisite for further processing. The issues of coal dust and fine coal granulation conducted to obtain homogeneous and persistent pieces for application in various branches of industry were presented. The article describes the binders and additives were applied in order to change the properties of the granules. The key factors affecting the process of fine-grained coal granulation is discussed. Granulated coal dust is most useful as an alternative fuel for combustion in industrial and household heating systems. However, carbon fuel requires a systematic control of the mechanical strength and resistance to external factors.
\end{abstract}

Keywords: granulation, fine coal, dusting, management, solid fuels

\section{INTRODUCTION}

Agglomeration of fine-grained material is most often carried out in the processes of briquetting and granulation [Pietsch 2008]. The durability of the obtained agglomerates depends on the method and parameters of the consolidation, material properties and the used binders [Cheng and Hsiau 2010] The type and share of the moisturizing liquid also have a large influence on the resistance of agglomerates [Bogdanov et al. 2012]. Agglomeration of fine-grained material is dictated by the following goals:

- elimination of dust formation during transport and storage,

- reduction of material losses in tailings,

- reduction of the leachability of soluble components,

- conferral of new specific properties to materials,

- creation of compound materials with the required grain size.

In the case of briquetting, the individual grains "united" under the influence of external forces. Depending on the geometry of the forming matrix applied in the press used for briquetting, the products are given an oval, barrel, cushion or saddle shape [Kosturkiewicz et al. 2014]. In the case of material extrusion in extruders or sieves, the products are often called pellets, which assume a cylindrical shape [Temmerman et al. 2006].

In the granulation, the merging of grains is the phenomenon of mutual sticking, under the influence of rotational movement and the gravity, centrifugal and capillary forces [Nelson 2005]. The most packed granules are obtained from the materials that meet the requirements of the grain pile [Iveson 2002]. The heterogeneous grain composition of the material causes the high porosity of the agglomerates and their low mechanical resistance [Pietsch 2008]. Increasing the strength of the lumps is possible by adding the appropriate binder to agglomeration material [Yoshizawa et al. 2004].

The granulation process is used in practice for the consolidation (pelleting) of iron ore and nonferrous metals, coal dust, mineral raw materials from mineral extraction and many fine-grained industrial wastes [Galos and Szlugaj 2014]. The aim of this work is to present the issues of coal sludge and dust granulation in terms of the possibility of obtaining useful products or raw materials and reducing dusting in the process of transportation, storage and further processing. 


\section{THE ISSUE OF COAL SLUDGE AND FINE COAL GRANULATION}

Granulation of brown coal dust and finegrained brown coal is usually carried out at the place of production of these wastes - on the mining and processing plants. Most often granulating materials are [Naumov et al. 2013]:

- coal and lignite dust as well as coking dust, constituting the charge for the coking and semi-coking process;

- coal sludge as separate solid fuels;

- and coal sludge and dust as fuel mixtures with the additives increasing their energy value;

- generator dust, smoke and other carbonaceous wastes as materials for the production of fuels with specific usable properties.

Fine coal waste and coal dust are most often processed to produce an alternative fuel. The calorific value is the basic criterion. The calorific value of the fuel obtained as a result of coal waste processing with granulation or briquetting method varies from $19 \mathrm{MJ} / \mathrm{kg}$ to $23 \mathrm{MJ} / \mathrm{kg}$ [Robak and Matuszek 2008]. The estimated amount of coal waste in Poland is 0.5 billion tons. Effective energy recovery is possible if the carbon content in the waste exceeds $8 \%$.

An example of the calorific value increase involves the agglomeration of the mixture of finegrained coal with the addition of biomass. Then agglomerates have been subjected to heat treatment for 15 minutes at $300-500^{\circ} \mathrm{C}$ [Faizal 2017]. As a result of carbonization, an increase in the calorific value of the fuel was observed, compared to the calorific value of nono-treated fuel.

The method of coal dust granulation to obtain a coal fuel for combustion in grate boilers is shown in Figure 1. The obtained fuel with the grain size exceeding $5 \mathrm{~mm}$ was characterized by a calorific value of $26-29 \mathrm{MJ} / \mathrm{kg}$ and the sulfur content of about $0.6 \%$ and ash below 15\% [Hycnar 2015].

Coal granulation was used for the production of alternative solid fuel intended for combustion

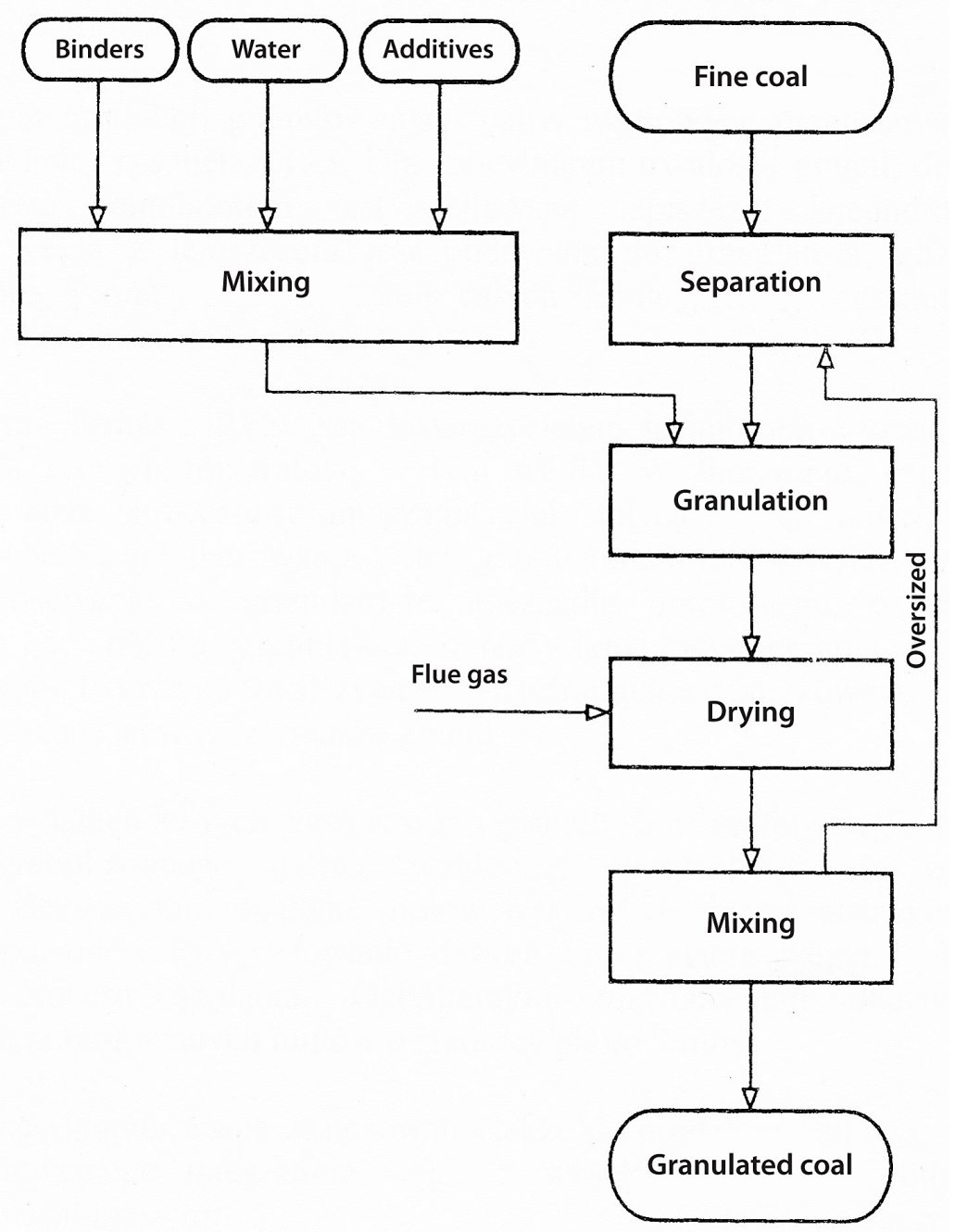

Figure 1. Scheme of fine coal granulation in order to obtain fuel for grate boilers combustion [Hycnar 2015] 
in fluidized bed furnaces. The use of granules as charge for stationary fluidized bed resulted in an increase of the combustion process efficiency [Zaostrovskii et al. 2012].

Previous laboratory works confirm that finegrained coals are preferably converted into granules in disk granulators [Feliks 2012]. Lime was used as a binder in the share from $1 \%$ to $1.5 \%$ d.m. The obtained granules were characterized by the size from 5 to $10 \mathrm{~mm}$. In industrial tests, intensive heating of the mixture of coal and lime should be considered, in order to evaporate the water before the granulation process is conducted.

The technology of granulated coal with the addition of lime $(\mathrm{CaO})$ is commonly used. Calcium oxide, owing to its sorption properties, reduces the moisture content and the $\mathrm{SO}_{2}$ emissions in the combustion process. Coal and lime granules have good energy properties and external resistance [Pyssa 2017].

Figure 2 shows a diagram of the coal fines granulation using a disk granulator with the diameter of $1.5 \mathrm{~m}$ at a speed of $15-20 \mathrm{rpm}$ and the inclination angle of the plate amounting to $40-45^{\circ}$ [Naumov et al. 2013]. The size of the granules ranged from 15 $\mathrm{mm}$ to $20 \mathrm{~mm}$. A binder was used in the form of an aqueous solution of lignosulphonate (wood industry waste) in the amount of $2-3 \%$ by mass. The granulation process was preceded with the heating of material in a specially constructed the vortex chamber, at a temperature of $430^{\circ} \mathrm{C}$. It was found that the mechanical strength of solids from the coal fines is comparable to the strength of the coal nuggets. The manufactured agglomerates are suitable for combustion in domestic heating furnaces; the obtained efficiency increased by $63-64 \%$, whereas the losses caused by incomplete combustion were reduced.

The granulated fine coal can be used as a replacement for aggregates. The mechanical properties of granules made with coal and ash, with a small addition of cement and water, were investigated [Yoshimoto et al. 2012]. It was found that the compression strength of granules depends on the type and size of the coal and ashes grains to a slight degree. However, the value of the internal stress in granules significantly depends on the type and size of the material. Solovei et al. [2016] shows the method of fine coal granulation in order to obtain mechanically durable spherical granules with a diameter from $1 \mathrm{~mm}$ to $6 \mathrm{~mm}, 3 \mathrm{~mm}$ on

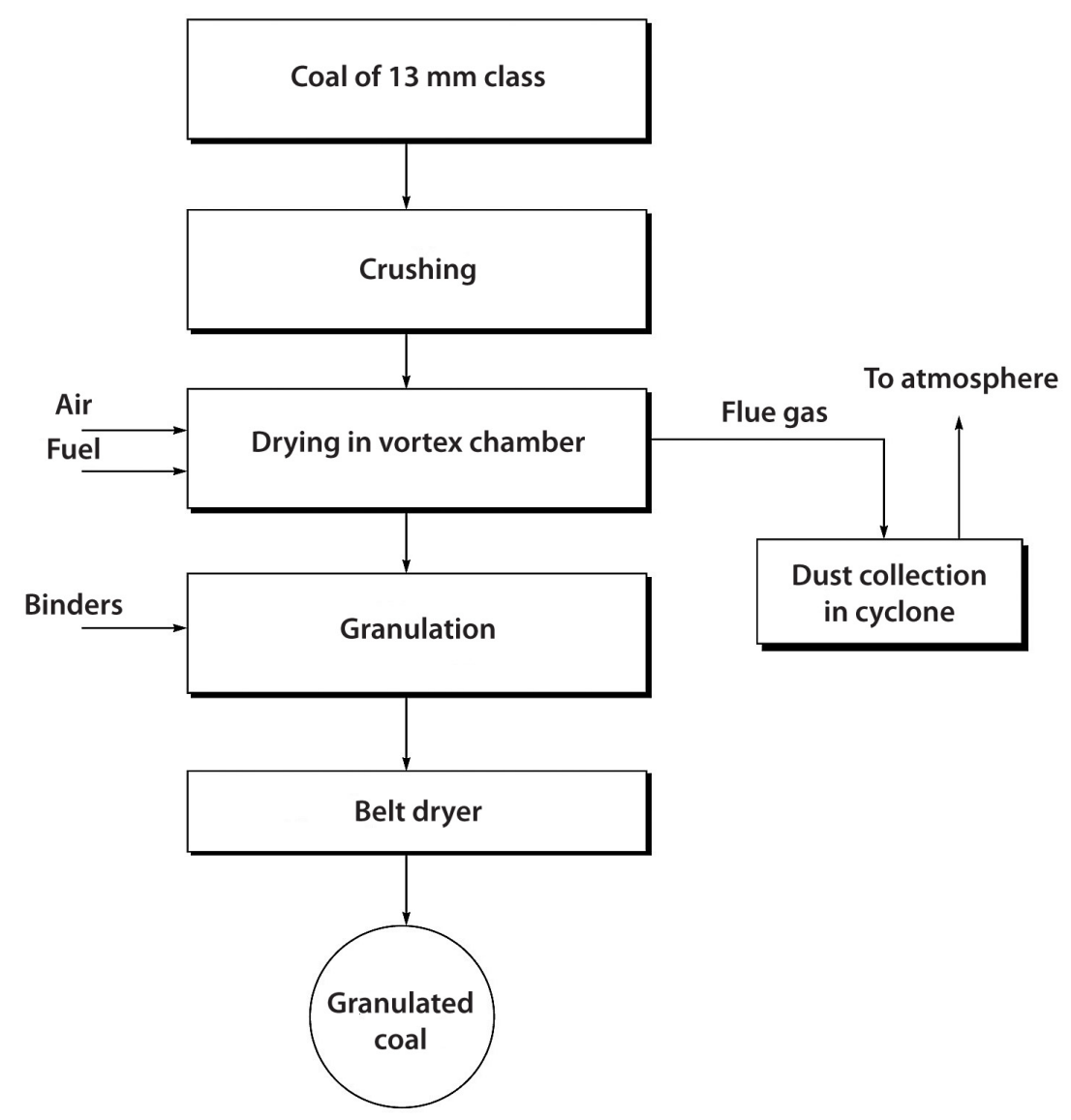

Figure 2. Diagram of coal dust granulation for the domestic heating fuel [Naumov et al. 2013] 
average. It has been presented that the composition of the material fraction for granulation can be significantly changed by the introduction of surfactant during the merging. Due to the favorable structural parameters and mechanical strength of the granules, they can be used as a deposit of moveable and fluidized filler in the adsorption processes.

Despite the favorable results of research works, granulation is not widespread in Poland for the processing of large quantities of fine-grained coal due to, among others, limited efficiency of granulators. The granulation of coal using drum and disk granulators is carried out only in small enterprises, and in relatively small quantities.

\section{THE SELECTION OF BINDERS FOR GRANULATION}

Coal dust and fine coal belong to the materials that are less susceptible to grains merging into the form of durable granule. Increasing the durability can be obtained by adding improving ingredients. These additives fulfill the following functions [Litster and Ennis 2013]:

- increase the mechanical strength of granules binders, adhesives;

- accelerate the process of granules consolidation - so-called catalysts;

- reduce the share of unbound water - so-called dehydrators;

- improve the determined physicochemical properties of the granulates;

- combine two or more of the above-mentioned functions - multifunctional additives.

Binders are used to increase the mechanical strength of granules, especially the compressive strength. Depending on the binder used, the granulate usually requires conditioning or additional heat treatment [Reynolds et al. 2005].

Dehydrators are added when the prepared raw materials contain too much water, thus hindering or preventing the granulation process. The added substances "bind" water and aid in bonding of the material grains; they may also increase their mechanical resistance [Karthikeyan et al. 2009].

Additives may improve the useful properties of granulate used for combustion as fuel in furnaces, by:

- reducing emissions of $\mathrm{SO}_{2}$ in the exhaust gas,

- reducing iron oxide,

- correcting the melting point of combustion ash.
The following substances are used as additives: asphalt, bentonite, cement, sodium chloride, calcium chloride, dextrin, clay, organic glue, starch, silica, sulphite lye, molasse, pitch, ferrous sulphate, water glass, synthetic polymers, limestones, lime [Kelbaliyev et al. 2013].

Brief characteristics of the selected substances and components constituting additives for granulating of fine coals are presented:

1) Bentonite binds excess water and increases the mechanical strength of granules for crushing. It consists mainly of montmorillonite, capable of forming gels with a developed surface. The sodium-activated bentonites have a swelling capacity of $600 \%$ to $900 \%$, but not-activated $200 \%$. The amount of bentonite added depends on the material moisture content and usually the share is from $0.5 \%$ to $1 \%$. The bentonite granules achieve the final strength within 4 to 6 hours after production.

2) Cement is often used as binder to merge multiple mineral materials. In the case of granulation, the cement share ranges from $2 \%$ to $15 \%$. The addition of cement to the granulated material reduces the amount of water bound in the granules. For coal granulation, it is advisable to use Portland cement or ground clinker cement, due to shortening the setting time of products.

3) Quicklime (calcium oxide $\mathrm{CaO}$ ) is a binder often used as a supplement to the granular coal. The lime binding properties are based on the formation of calcite skeleton as a result of the reaction of calcium hydroxide with carbon dioxide:

$$
\mathrm{Ca}(\mathrm{OH})_{2}+\mathrm{CO}_{2}=\mathrm{CaCO}_{3}+\mathrm{H}_{2} \mathrm{O}
$$

The lime oxide reacts with the water to form calcium hydroxide, with the release of heat:

$$
\mathrm{CaO}+\mathrm{H}_{2} \mathrm{O}=\mathrm{Ca}(\mathrm{OH})_{2}
$$

This process is long-lasting; therefore granules require conditioning (seasoning) of up to 60 days. Acceleration of the conditioning process can be achieved by placing the granules in $\mathrm{CO}_{2}$. As a result of the conditioning, an increase in granules strength is achieved, but upon reaching maximum, a decline of strength follows.

Lime contributes to the reduction of $\mathrm{SO}_{2}$ emissions in combustion gases, as illustrated by the following reactions:

- the process of burning sulphur compounds contained in the fuel

$$
\mathrm{S}+\mathrm{O}_{2}=\mathrm{SO}_{2}
$$


- the calcium hydroxide dehydration process

$$
\mathrm{Ca}(\mathrm{OH})_{2}=\mathrm{CaO}+\mathrm{H}_{2} \mathrm{O}
$$

- the process of calcium carbonate decalcination

- $\mathrm{SO}_{2}$ bonding process

$$
\mathrm{CaCO}_{3}=\mathrm{CaO}+\mathrm{CO}_{2}
$$

$$
\begin{gathered}
\mathrm{Ca}(\mathrm{OH})_{2}+\mathrm{SO}_{2}=\mathrm{CaSO}_{3}+\mathrm{H}_{2} \mathrm{O} \\
\mathrm{CaCO}+\mathrm{SO}_{2}=\mathrm{CaSO}_{3}+\mathrm{CO}_{2} \\
\mathrm{CaO}+\mathrm{SO}_{2}=\mathrm{CaSO}_{3} \\
\mathrm{CaSO}_{3}+\mathrm{O}_{2}=\mathrm{CaSO}_{4}
\end{gathered}
$$

The share of manufactured sulphite and calcium sulphate compounds ranges from $30 \%$ to $80 \%$. The amount of $\mathrm{SO}_{2}$ removed from the exhaust is proportional to the lime added [Ozbas et al. 2002].

4) Limestone affects the reduction of the $\mathrm{SO}_{2}$ proportion in the exhaust, similarly to the addition of lime for the granulation of coal. Natural limestone, dolomite and chalk are used as additives.

5) High-sodium water glass is also used as a binding additive. Typically, the addition of phosphoric acid is used for gelation and skeleton formation.

6) Water-asphalt emulsions are added to the agglomerated material in the amount of $5 \%$ to $10 \%$. This emulsion makes granules hydrophobic and resistant to frost.

7) Molasses, starch and dextrin are additives, which effectively bind coal grains in the case, where the granules are subjected to thermal treatment.

8) Organic resins (carbamide, polyvinyl and acrylic) can be also added in the form of solutions and aqueous suspensions in the agglomeration of fine coal.

The choice of a suitable substance as a binder to coal granulation usually affects the physicochemical and functional properties of the product. The above-mentioned additives do not pose a threat to the environment, are easily available and relatively cheap.

\section{FACTORS AFFECTING THE GRANULATION}

In the fine coal granulation to solid fuel, the organizational and production factors should be taken into account, including:
- defining the requirements for granulated carbonaceous fuels,

- selecting raw materials and additives,

- developing the mixture preparation,

- developing granulation methodology,

- determining the way of granulate conditioning,

- establishing requirements for product store and transport,

- determining term conditions of granular fuel combustion.

The requirements for granular fuels are determined by the main recipients (users). In the case of the production of granular fuel with reduced emissions of $\mathrm{SO}_{2}$ during combustion, the amount of added calcium compounds should be precisely determined. When adding limestone, thorough mixing is required before the granulation, taking into account the efficiency and load on the granulator [van Netten et al. 2015].

The selected raw materials must guarantee obtaining the appropriate calorific value as well as the share of ash and sulfur compounds. Using excessive amounts of binders, or other additives, results in the decline of energy parameters [Purohit et al. 2006].

In the process of fine coal granulation, the knowledge of grain composition and water content are important [Zawiaślak et al. 2010]. Increasing the water content in the material reduces the mechanical strength of the granules. In the case of increased hydration of the granulated blend, the water binding binders can be used. When the water content is insufficient, it should be added by sprinkling during granulation. Sprinkling with water or suspension makes the merging the grains much easier.

The way of material charging and water spraying to the granulator should be considered. In the disk granulation some other relevant factors are also taken for the segregation effect: number of disc rotations, the inclination angle, height and diameter of the plate [Holger and Lampke 2016] (Figure 3).

The size of the granules can vary greatly due to non-homogeneous graining, as well as non-uniform hydration and material feeding to the granulator. In order to obtain homogeneous material, the grain fractions are classified. The addition of a binder usually requires the conditioning of granules in order to obtain the required mechanical strength [Agusta et al. 2017]. Granular solid fuels are usually not very resistant to water and require storage and transport protected against hydration. 

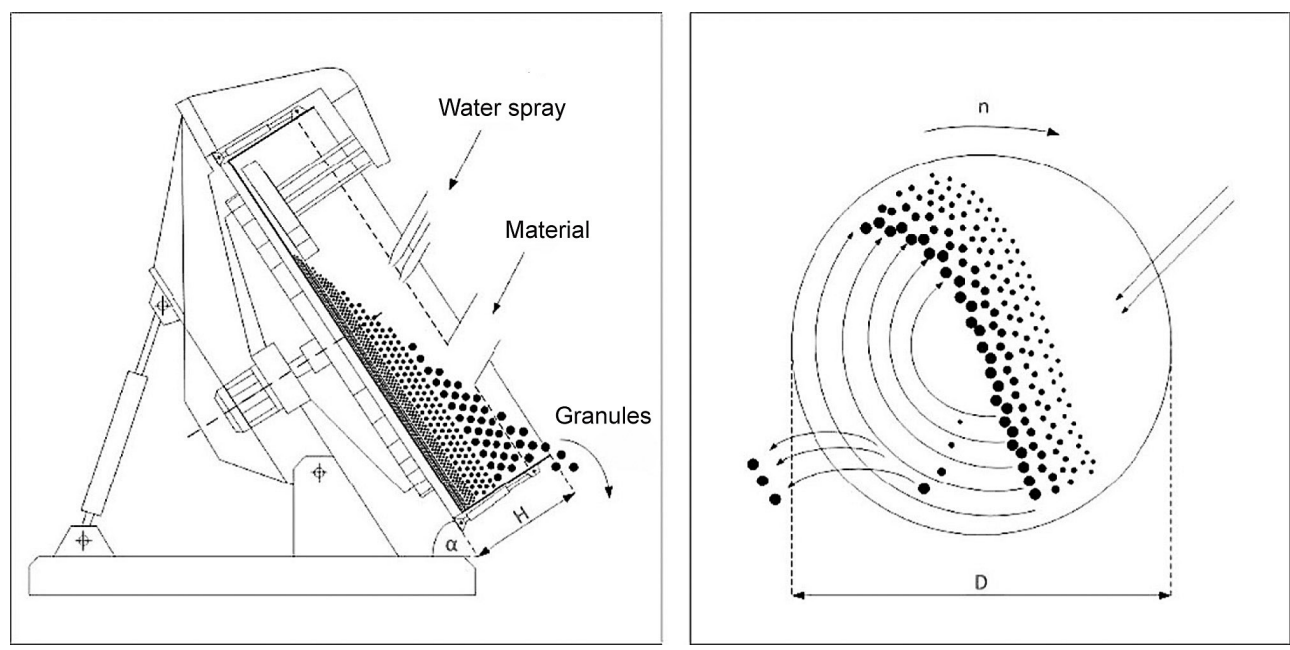

Figure 3. Disc granulator with segregation effect: $n$ - number of disc rotations, $\alpha$ - the inclination angle, $H$ - height of the side wall, $D$ - diameter of the plate [Holger and Lampke 2016]

In the case of production of granules requiring additional thermal treatment, they are sent directly to the tunnels or drying drums after their production. In order to accelerate the process of carbonization, the granules with calcium binders are exposed to $\mathrm{CO}_{2}$ at a temperature of $40^{\circ} \mathrm{C}$ to $60^{\circ} \mathrm{C}$ [Ivanov et al. 2003]. This process allows shortening the seasoning of granules by up to several hours.

\section{CONCLUSIONS}

The following conclusions related to granulation of fine coal can be drawn:

1. Fine-grained coals, including sludge and fine coal, are mostly agglomerated to reduce dust and produce solid fuels for combustion in boilers.

2. Agglomeration can be carried out by briquetting or granulation; granulation is less energyintensive and less efficient.

3. The process of coal granulation is carried out with additions that affect the properties of agglomerates.

4. The most useful additives in the mixture are binders, such as: calcium hydroxide, cement, water glass, asphalts, polymers and organic adhesives.

5. The final mechanical strength of the granules is attained by the seasoning from several hours to several dozen days.

6 . The manufacturing of coal granules requires continuous control of production parameters as well as the quality of products.

\section{REFERENCES}

1. Agusta H., Nisya F.N., Iman R.N., Bilad D.B.C. 2017. Granulation of coal fly ash by using different types of granule agents. IOP Conf. Series: Earth and Environmental Science, 65(1), doi: 10.1088/1755-1315/65/1/012023.

2. Bogdanov B., Hristov Y., Markovska I., Rusev D., Georgiev D. 2012. Coal fly ash granulation and determination of granule physicomechanical properties, Oxidation Communication, 35( 1), 228-238.

3. Cheng H.J., Hsiau S.S. 2010. The study of granular agglomeration mechanism. Powder Technology, 199(3), 272-283, doi: https://doi.org/10.1016/j. powtec.2010.01.016.

4. Faizal M. 2017. Utilization biomass and coal mixture to produce alternative solid fuel for reducing emission of greenhouse gas. International Journal on Advanced Science Engineering Information Technology, 7 (3), 950-956.

5. Fecko P., Tora B., Tod M. 2013. Coal waste: handling, pollution impacts and utilization. In: $D$. Osborne $(E d$.) The Coal Handbook: Towards Cleaner Production. Coal Utilisation. Vol. 2 in Woodhead Publishing Series in Energy, Pages 63-84, doi: https://doi.org/10.1533/9781782421177.1.63.

6. Feliks J. 2012. Laboratory testing of coal sludge granulation. Chemik, 66(5), 388-395.

7. Galos K., Szlugaj J. 2014. Management of hard coal mining and processing wastes in Poland. Mineral Resources Management - Gospodarka Surowcami Mineralnymi, 30(4), 51-63, doi: https://doi. org/10.2478/gospo-2014-0039.

8. Holger L., Lampke J. 2016. Technical and economic aspects of granulation of coal. In: Litvinenko V. (eds) XVIII International Coal Preparation Congress, Springer, Cham, pp. 383-389, doi: https:// doi.org/10.1007/978-3-319-40943-6_57. 
9. Hycnar J.J., 2015. Methods of increasing the calorific value of fine coal waste. Inżynieria Mineralna - Journal of the Polish Mineral Engineering Society, 16(1), 33-55.

10. Ivanov I.P., Sudakova I.G., Kuznetsov B.N. 2003. Manufacture of briquetted and granulated fuels from lignite with biobinders and heated die. Chemistry for Sustainable Development, 11, 847-852.

11. Iveson S.M., 2002. Limitations of one-dimensional population balance models of wet granulation processes. Powder Technology, 124(3), 219-229, doi: https://doi.org/10.1016/S0032-5910(02)00026-8.

12. Karthikeyan M., Zhonghua W., Mujumdar A.S. 2009. Low-rank coal drying technologies - current status and new developments. Drying Technology An International Journal, 27(3), 403-415, doi: https://doi.org/10.1080/07373930802683005.

13. Kelbaliyev G.I., Samedli V.M., Samedov M.M., Kasimova R.K. 2013. Experimental study and calculation of the effect of intensifying additives on the strength of superphosphate granules. Russian Journal of Applied Chemistry, 86(10), 1478-1482, doi: https://doi.org/10.1134/S1070427213100030.

14. Kosturkiewicz B., Janewicz A., Magdziarz A. 2014. Results of briquetting and combustion process on binder-free coking coal. Polish Journal of Environmental Studies, 23(4), 1385-1389.

15. Litster J., Ennis B. 2013. The Science and Engineering of Granulation Processes. Springer Science \& Business Media, pp. 250.

16. Makkonen H.T., Heino J., Laitila L., Hiltunen A., Pöyliö E., Härkki J., 2002. Optimisation of steel plant recycling in Finland: dusts, scales and sludge. Resources, Conservation and Recycling, 35(1-2), 77-84, doi: https://doi.org/10.1016/S0921-3449(01)00123-9.

17. Naumov K.I., Maloletnev A.S., Mazneva O.A. 2013. Advanced processes for manufacturing agglomerated fuel from fine coals. Solid Fuel Chemistry, 47(1), 47-55, doi: https://doi.org/10.3103/ S0361521912060080.

18. Nelson S.O. 2005. Density-permittivity relationships for powdered and granular materials. IEEE Transactions on Instrumentation and Measurement, 54(5), 2033-2040, doi: 10.1109/TIM.2005.853346.

19. Ozbas K.E., Hiçyilmaz C., Kok M.V. 2002.The effect of lime addition on the combustion properties and sulfur contents of three different coals. Energy Sources, 24(7), 643-652, doi: https://doi.org/10.10 80/00908312.2002.11877439.

20. Pasiowiec P., Hycnar J.J., Tora B. 2016. Fine coal waste utilisation. Inżynieria Mineralna - Journal of the Polish Mineral Engineering Society, 17(1), 213-222.

21. Patil D.P., Taulbee D., Parekh B.K., Honaker R. 2009. Briquetting of coal fines and sawdust - effect of particle-size distribution. International Journal of Coal Preparation and Utilization, 29, 251-264.

22. Pietsch W.B. 2008. Agglomeration Processes: Phenomena, Technologies, Equipment. John Wiley \& Sons, pp. 622.

23. Purohit P., Tripathi A.K., Kandpal T.C. 2006. Energetics of coal substitution by briquettes of agricultural residues. Energy, 31(8-9), 1321-1331, doi: https://doi.org/10.1016/j.energy.2005.06.004.

24. Pyssa J. 2017. Extractive waste from hard coal mining in Poland - balance, status of management and environmental aspects. E3S Web of Conferences "Energy and Fuels 2016", 14, 02024, doi: 10.1051/ e3sconf/201 71402024.

25. Reynolds G.K., Fu J.S., Cheong Y.S., Hounslow M.J., Salman A.D. 2005. Breakage in granulation: A review. Chemical Engineering Science, 60(14), 3969-3992, doi: https://doi.org/10.1016/j.ces.2005.02.029.

26. Robak J., Matuszek K. 2008. Granulated fuels from wastes (in Polish). Chemik, 61(9), 418-424.

27. Solovei V.N., Spiridonova E.A., Samonin V.V., Khrylova E.D., Podvyaznikov M.L. 2016. Synthesis of spherically shaped granulated carbon sorbent. Russian Journal of Applied Chemistry, 89(7), 1102-1108, doi: https://doi.org/10.1134/ S1070427216070090.

28. Temmerman M., Rabier F., Jensen P.D., Hartmann H., Böhm T. 2006. Comparative study of durability test methods for pellets and briquettes. Biomass and Bioenergy, 30, 964-972.

29. van Netten K., Moreno-Atanasio R., Galvin K.P. 2015. A kinetic study of a modified fine coal agglomeration process. Procedia Engineering, 102, 508-516, doi: https://doi.org/10.1016/j.proeng.2015.01.201.

30. Yoshimoto N., Hyodo M., Nakata Y., Orense R.P., Hongo T., Ohnaka A. 2012. Evaluation of shear strength and mechanical properties of granulated coal ash based on single particle strength, Soils and Foundations, 52(2), 321-334, doi: https://doi. org/10.1016/j.sandf.2012.02.009.

31. Yoshizawa Y., Hirao K., Kanzaki S. 2004. Fabrication of low cost fine-grained alumina powders by seeding for high performance sintered bodies. Journal of the European Ceramic Society, 24(2), 325-330, doi: https://doi.org/10.1016/S09552219(03)00226-7.

32. Zaostrovskii A.N., Sarychev V.D., Umanskii A.A., Murko V.I. 2012. Thermal analysis of coal and water-coal suspensions. Coke and Chemistry, 55(1), 10-14, doi: https://doi.org/10.3103/ S1068364X12010085.

33. Zawiślak K., Sobczak P., Panasiewicz M., Markowska A. 2010. Influence of chosen technological parameters on the kinetic durability of pellets (in Polish). Acta Scientiarum Polonarum, Technica Agraria, 9(1-2), 3-10. 